\title{
Common names decreased in Japan: Further evidence of an increase in individualism
}

\author{
Yuji Ogihara* \\ Institute of Arts and Sciences, Tokyo University of Science, Shinjuku-ku, Japan \\ *Corresponding author. Email: yogihara@rs.tus.ac.jp
}

(Received 24 July 2021; Revised 31 October 2021; Accepted 01 November 2021)

\begin{abstract}
Previous research has demonstrated that unique names increased in Japan, which shows a rise in uniquenessseeking and individualism. To increase the validity of the prior findings, it is important to confirm the robustness of their results. Therefore, this study examined another indicator of historical changes in names in Japan. Specifically, I investigated whether the rates of common names decreased in Japan between 2004 and 2018. The dataset used in the previous study was analyzed. The results consistently showed that the rates of common names decreased for both boys and girls for the period. These results were consistent with the previous research, which further increases the validity of the finding that Japanese culture became more individualistic.
\end{abstract}

Key words: name; individualism; uniqueness; baby; cultural change

\section{Introduction}

Ogihara et al. (2015) demonstrated that the rates of common Chinese characters used in baby names increased but the rates of common readings decreased in Japan between 2004 and 2013. Further, they showed that writing variations of names decreased, but reading variations increased for the period. Taken together, these results were interpreted to indicate that parents came to give unique names by assigning more common Chinese characters but reading them uncommonly. Thus, this research shows an increase in uniqueness-seeking and individualism in Japan. This shift toward greater individualism has also been reported in other cultural aspects in Japan (Hamamura, 2012; Ogihara, 2017b; 2018b; 2020b; Taras et al., 2012; for reviews, see Ogihara, 2017a; 2018a).

These results may be difficult to understand especially for non-native Japanese speakers because names and naming practices in Japan are different from those in other cultures. In Japan, three types of characteristics can be used for names: hiragana, katakana, and Chinese characters. Hiragana and katakana are phonograms, which are symbols representing speech sounds without reference to meanings (e.g., alphabet). Thus, writings and readings of hiragana and katakana are fixed. In contrast, Chinese characters are ideograms, which are symbols representing concepts without reference to sounds. Thus, writings and readings of Chinese characters are not fixed. Importantly, people can give any readings to a Chinese character used for baby names. For example, a common writing for a boys' name “大翔” has at least 18 variations of readings (Ogihara, 2021c). This naming practice makes it possible to give unique names in Japan (for patterns of uncommon names, see Ogihara, 2015; 2021b).

\footnotetext{
(๑) The Author(s), 2021. Published by Cambridge University Press. This is an Open Access article, distributed under the terms of the Creative Commons Attribution licence (http://creativecommons.org/licenses/by/4.0), which permits unrestricted re-use, distribution and reproduction, provided the original article is properly cited.
} 
Moreover, Ogihara (2021a) directly examined whether the rates of unique names, rather than common names, increased by analyzing datasets of baby names that includes both writings and readings. This shows that unique names increased in Japan between 2004 and 2018, consistent with the prior study (Ogihara et al., 2015).

It is important to empirically confirm whether these prior findings are valid and robust. Indeed, the reproducibility of science is considered valuable (e.g., Open Science Collaboration, 2012; 2015). Therefore, this study analyzed another indicator of names that had not been investigated in Ogihara (2021a): temporal changes in the rates of common names. Based on the previous findings that unique names increased in Japan (Ogihara, 2021a), it was hypothesized that the rates of common names had decreased in Japan.

\section{Method}

\subsection{Data}

I analyzed the data that are open to the public (https://doi.org/10.17605/OSF.IO/2WURJ; for details, see Ogihara, 2020a) and have been used in previous research (Ogihara, 2021a; 2021c).

The data were from annual surveys conducted by the Meiji Yasuda Life Insurance Company between 2004 and 2018 (Meiji Yasuda Life Insurance Company, 2020; Ogihara, 2020a). To be more specific, the data were generated from lists of readings in the top 10 most common writings, which are published by Meiji Yasuda. Although the top 10 writings are common, their readings can differ within each writing. Thus, each name is not necessarily common. For instance, a common writing “大羊羽” has many readings, such as “Hiroto," “Haruto," “Yamato," and “Tsubasa”, but the name that is written as “大翔” and read "Tsubasa" is uncommon (Ogihara, 2021c).

Sample sizes for each year are summarized in Table 1 . The average annual sample sizes for the raw data were 251 for boys and 268 for girls. The total sample sizes were 3,762 for boys and 4,017 for girls. The average annual sample sizes for the original surveys were 5,242 for boys and 4,958 for girls. The total sample sizes were 78,623 for boys and 74,372 for girls.

\subsection{Indicator}

The rates of the top 10 most common names were calculated separately for boys and girls because many prior studies used this rate as the main indicator (e.g., Ogihara et al., 2015; Varnum \& Kitayama, 2011). The top 10 most common names were determined by absolute frequencies. For example, they included 大翔 (ひろと: Hiroto) and 蓮 (れん: Ren) for boys' names and 陽菜 (ひな: Hina) and さくら (Sakura) for girls' names. Moreover, to confirm whether the results were robust, the rates of the top 5 and 15 most common names were calculated. ${ }^{1}$ If the phenomenon of a decrease in common names was robust, then consistent results should be observed, regardless of these indicators.

\subsection{Analysis}

First, I computed the percentage of each individual name among the total sample size of the original surveys. Then, I calculated the percentage of the top 5, 10, and 15 most common names in each year. In this calculation, when more than 5,10 , or 15 names were included in the common names, the percentage was adjusted (e.g., 11 names in the top 10 most common names due to a duplicated rank).

Next, I calculated two indices: correlation with year $(r)$ and annual change (\%). Correlation with year indicates how each percentage of common names increased, decreased, or did not change over time.

\footnotetext{
${ }^{1}$ The smallest number of name variations included in the dataset was 16 (for girls in 2007). Thus, the rate of the top 15 most common names was used as an indicator (for details, see Ogihara, 2020a).
} 
Table 1. Sample sizes for each year

\begin{tabular}{|c|c|c|c|c|c|c|c|c|c|c|c|c|c|c|c|c|c|c|}
\hline & & 2004 & 2005 & 2006 & 2007 & 2008 & 2009 & 2010 & 2011 & 2012 & 2013 & 2014 & 2015 & 2016 & 2017 & 2018 & Total & Average \\
\hline \multirow{3}{*}{$\begin{array}{c}\text { Present } \\
\text { data }\end{array}$} & Boys & 235 & 204 & 193 & 243 & 261 & 207 & 175 & 176 & 148 & 297 & 201 & 216 & 417 & 324 & 465 & 3,762 & 251 \\
\hline & Girls & 262 & 194 & 247 & 248 & 224 & 237 & 184 & 161 & 196 & 299 & 234 & 209 & 439 & 387 & 496 & 4,017 & 268 \\
\hline & Total & 497 & 398 & 440 & 491 & 485 & 444 & 359 & 337 & 344 & 596 & 435 & 425 & 856 & 711 & 961 & 7,779 & 519 \\
\hline \multirow{3}{*}{$\begin{array}{l}\text { Original } \\
\text { survey }\end{array}$} & Boys & 4,861 & 4,292 & 4,409 & 4,591 & 4,621 & 4,595 & 4,078 & 3,648 & 3,388 & 5,338 & 3,481 & 4,278 & 8,947 & 8,300 & 9,796 & 78,623 & 5,242 \\
\hline & Girls & 4,419 & 4,082 & 4,167 & 4,204 & 4,275 & 4,254 & 3,805 & 3,503 & 3,222 & 5,026 & 3,273 & 4,122 & 8,509 & 8,030 & 9,481 & 74,372 & 4,958 \\
\hline & Total & 9,280 & 8,374 & 8,576 & 8,795 & 8,896 & 8,849 & 7,883 & 7,151 & 6,610 & 10,364 & 6,754 & 8,400 & 17,456 & 16,330 & 19,277 & 152,995 & 10,200 \\
\hline
\end{tabular}


Annual change indicates the extent to which each percentage of common names varied. For this index, I conducted a simple regression analysis in which the year was an independent variable and the percentage of common name was a dependent variable. In this calculation, a significance test was not conducted. This was because the data points were not considered independent, which is necessary to conduct a significance test. Analyses were conducted both weighing and unweighting the sample sizes of individual years (e.g., Clark et al., 2015; Li et al., 2020; Ogihara, 2019; 2020c; Ogihara et al., 2015; Ogihara \& Kusumi, 2020; Park et al., 2016).

\section{Results}

In all the analyses using the three different indicators (top 5, 10, and 15), the rates of common names decreased for both boys and girls between 2004 and 2018 (Table 2 and Figure 1).

Moreover, these results were consistently found when the sample sizes were not weighted (Table 2 and Figure 2).

\section{Discussion}

As predicted, the rates of common names decreased for both boys and girls between 2004 and 2018 in Japan, showing an increase in uniqueness-seeking and individualism. These results are consistent with previous research on names (Ogihara, 2021a; Ogihara et al., 2015), confirming that the prior findings are valid and robust. Furthermore, these results are also consistent with prior research on other aspects of Japanese culture (Hamamura, 2012; Ogihara, 2017b; 2018b; Taras et al., 2012; for reviews, see Ogihara, 2017a; 2018a). Therefore, this research contributes to the existing literature by providing further evidence of the rise in uniqueness-seeking and individualism in Japan.

The increase in unique names has also been suggested in other nations such as Germany (Gerhards \& Hackenbroch, 2000), the United States (Twenge et al., 2010; 2016), and China (Cai et al., 2018; but also see Ogihara, 2020d). Thus, this phenomenon may be found more broadly.

Table 2. Historical changes in the percentages of common names

\begin{tabular}{|c|c|c|c|c|}
\hline & Sex & Indicator & Correlation with year $(r)$ & Annual change (\%) \\
\hline \multirow[t]{6}{*}{ Weighting sample sizes } & \multirow[t]{3}{*}{ Boys } & Top 5 & -.387 & -.024 \\
\hline & & Top 10 & -.506 & -.052 \\
\hline & & Top 15 & -.313 & -.037 \\
\hline & \multirow[t]{3}{*}{ Girls } & Top 5 & -.376 & -.028 \\
\hline & & Top 10 & -.281 & -.022 \\
\hline & & Top 15 & -.306 & -.052 \\
\hline \multirow[t]{6}{*}{ Not weighting sample sizes } & \multirow[t]{3}{*}{ Boys } & Top 5 & -.267 & -.019 \\
\hline & & Top 10 & -.389 & -.044 \\
\hline & & Top 15 & -.175 & -.023 \\
\hline & \multirow[t]{3}{*}{ Girls } & Top 5 & -.288 & -.023 \\
\hline & & Top 10 & -.218 & -.020 \\
\hline & & Top 15 & -.229 & -.045 \\
\hline
\end{tabular}



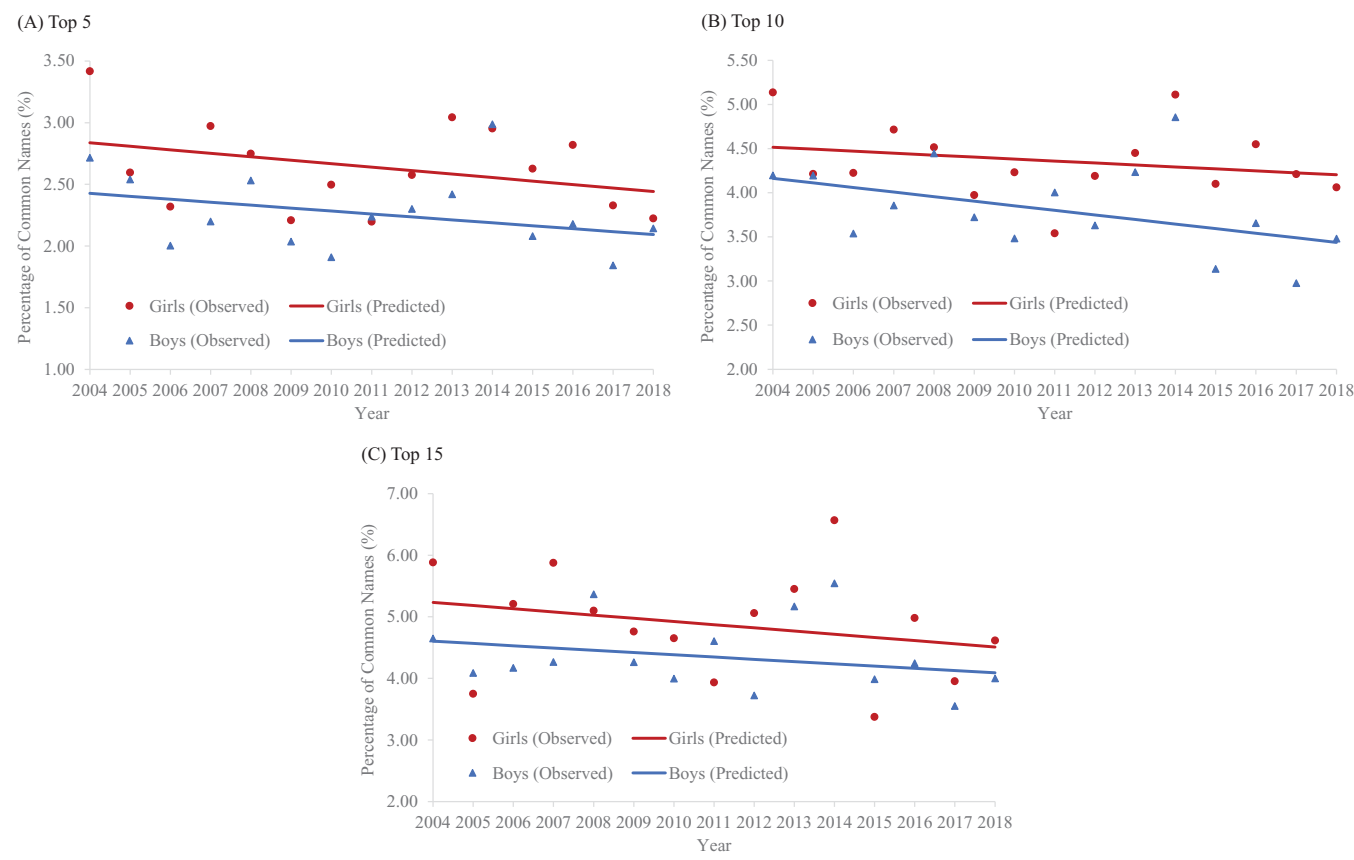

Figure 1. Percentages of common names, 2004-2018 (weighting sample sizes).
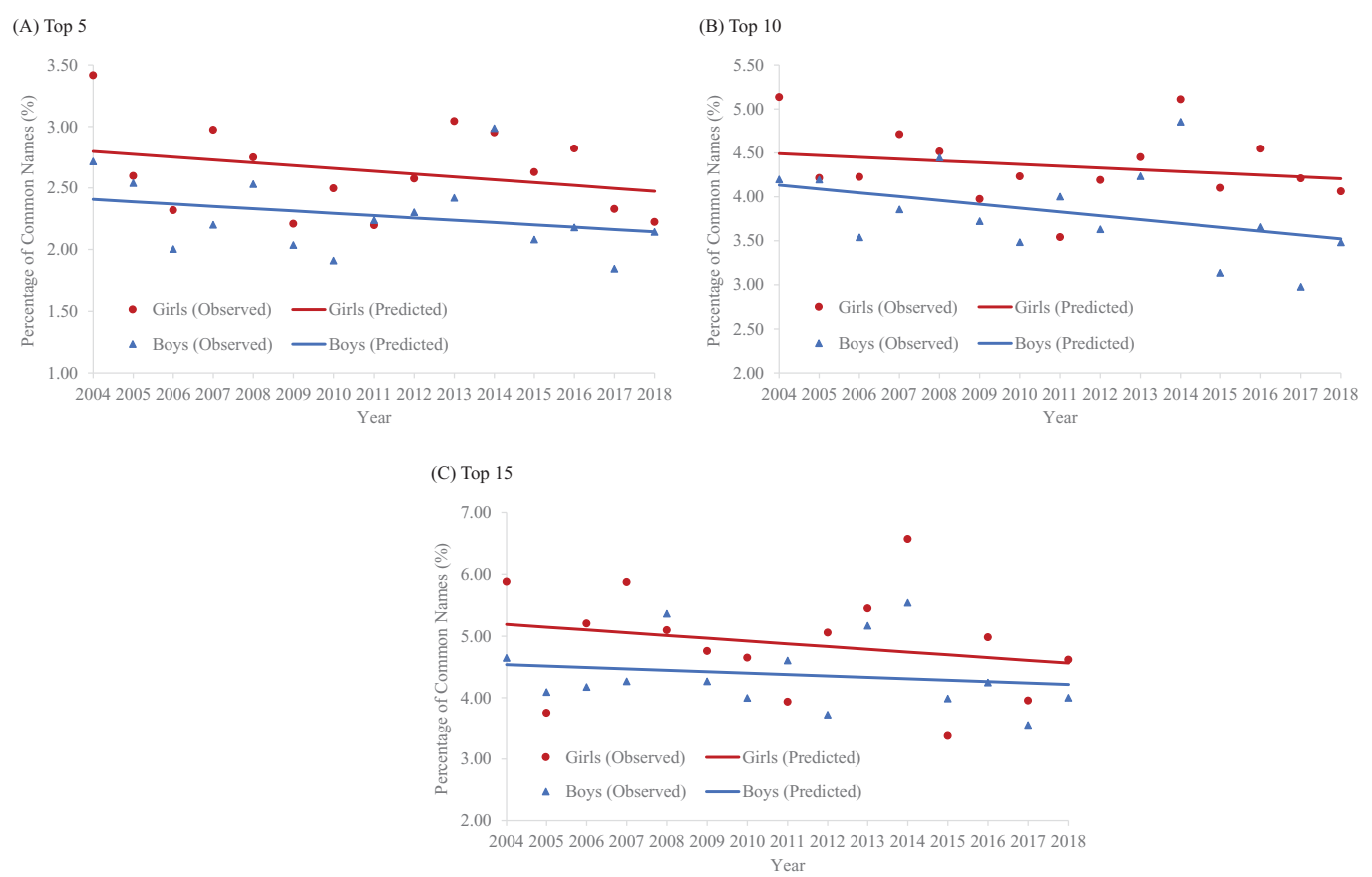

Figure 2. Percentages of common names, 2004-2018 (unweighting sample sizes).

As a limitation, it is unclear why Japanese culture has become more individualistic. There are many factors which influence individualism such as economic affluence (e.g., Grossmann \& Varnum, 2015), subsistence style (e.g., Talhelm, 2020), relational mobility (e.g., Yuki \& Schug, 2020), and residential 
mobility (e.g., Choi \& Oishi, 2020). Future studies should examine the relationships between these possible factors and the historical changes in individualism in Japan.

Acknowledgment. None.

Authorship contribution. The author confirms being the sole contributor of this work and has approved it for publication.

Funding statement. This research received no specific grant from any funding agency, commercial, or not-for-profit sectors.

Conflict of interest. The author declares no competing interests.

Data availability statement. The datasets analyzed during the current study are available in the Open Science Framework: https://doi.org/10.17605/OSF.IO/2WURJ (for details, see Ogihara, 2020a).

\section{References}

Cai, H., Zou, X., Feng, Y., Liu, Y., \& Jing, Y. (2018). Increasing need for uniqueness in contemporary China: Empirical evidence. Frontiers in Psychology, 9, 554. https://doi.org/10.3389/fpsyg.2018.00554

Choi, H., \& Oishi, S. (2020). The psychology of residential mobility: A decade of progress. Current Opinion in Psychology, 32, 72-75. https://doi.org/10.1016/j.copsyc.2019.07.008

Clark, D. M. T., Loxton, N. J., \& Tobin, S. J. (2015). Declining loneliness over time: Evidence from American colleges and high schools. Personality and Social Psychology Bulletin, 41, 78-89. https://doi.org/10.1177/0146167214557007

Gerhards, J., \& Hackenbroch, R. (2000). Trends and causes of cultural modernization: An empirical study of first names. International Sociology, 15, 501-531. https://doi.org/10.1177/026858000015003004

Grossmann, I., \& Varnum, M. E. (2015). Social structure, infectious diseases, disasters, secularism, and cultural change in America. Psychological Science, 26, 311-324. https://doi.org/10.1177/0956797614563765

Hamamura, T. (2012). Are cultures becoming individualistic? A cross-temporal comparison of individualism-collectivism in the United States and Japan. Personality and Social Psychology Review, 16, 3-24. https://doi.org/10.1177/1088868311411587

Li, L. M. W., Li, W. Q., Mei, D., \& Wang, Y. (2020). Self-esteem among Chinese cohorts: Its temporal trend and its relationships with socioecological factors, 1993-2016. European Journal of Personality, 34, 203-214. https://doi.org/10.1002/per.2238

Meiji Yasuda Life Insurance Company. (2020). Umare Doshi Betsu no Namae Chosa [Annual survey on baby names]. http:// www.meijiyasuda.co.jp/enjoy/ranking/index.html

Ogihara, Y. (2015). Characteristics and patterns of uncommon names in present-day Japan. Journal of Human Environmental Studies, 13, 177-183. https://doi.org/10.4189/shes.13.177

Ogihara, Y. (2017a). Temporal changes in individualism and their ramification in Japan: Rising individualism and conflicts with persisting collectivism. Frontiers in Psychology, 8, 695. https://doi.org/10.3389/fpsyg.2017.00695

Ogihara, Y. (2017b). Temporal changes in pay-for-performance systems in Japan: A decrease in seniority systems and an increase in annual salary systems (1991-2016). Studies in Science and Technology, 6, 149-158. https://doi.org/10.11425/ sst.6.149

Ogihara, Y. (2018a). Economic shifts and cultural changes in individualism: A cross-temporal perspective. In A.Uskul \& S.Oishi (Eds.), Socioeconomic environment and human psychology: Social, ecological, and cultural perspectives (pp. 247-270). Oxford University Press. https://doi.org/10.1093/oso/9780190492908.003.0010

Ogihara, Y. (2018b). The rise in individualism in Japan: Temporal changes in family structure, 1947-2015. Journal of CrossCultural Psychology, 49, 1219-1226. https://doi.org/10.1177/0022022118781504

Ogihara, Y. (2019). A decline in self-esteem in adults over 50 is not found in Japan: Age differences in self-esteem from young adulthood to old age. BMC Research Notes, 12, 274. https://doi.org/10.1186/s13104-019-4289-x

Ogihara, Y. (2020a). Baby names in Japan, 2004-2018: Common writings and their readings. BMC Research Notes, $13,553$. https://doi.org/10.1186/s13104-020-05409-3

Ogihara, Y. (2020b). Regional differences in individualism in Japan: Scoring based on family structure. Frontiers in Psychology, 11, 1677. https://doi.org/10.3389/fpsyg.2020.01677

Ogihara, Y. (2020c). The pattern of age differences in self-esteem is similar between males and females in Japan: Gender differences in developmental trajectories of self-esteem from childhood to old age. Cogent Psychology, 7, 1756147. https:// doi.org/10.1080/23311908.2020.1756147

Ogihara, Y. (2020d). Unique names in China: Insights from research in Japan-Commentary: Increasing need for uniqueness in contemporary China: Empirical evidence. Frontiers in Psychology, 11, 2136. https://doi.org/10.3389/fpsyg.2020.02136

Ogihara, Y. (2021a). Direct evidence of the increase in unique names in Japan: The rise of individualism. Current Research in Behavioral Sciences, 2, 100056. https://doi.org/10.1016/j.crbeha.2021.100056

Ogihara, Y. (2021b). How to read uncommon names in present-day Japan: A guide for non-native Japanese speakers. Frontiers in Communication, 6, 631907. https://doi.org/10.3389/fcomm.2021.631907 
Ogihara, Y. (2021c). I know the name well, but cannot read it correctly: Difficulties in reading recent Japanese names. Humanities and Social Sciences Communications, 8, 151. https://doi.org/10.1057/s41599-021-00810-0

Ogihara, Y., Fujita, H., Tominaga, H., Ishigaki, S., Kashimoto, T., Takahashi, A., Toyohara, K., \& Uchida, Y. (2015). Are common names becoming less common? The rise in uniqueness and individualism in Japan. Frontiers in Psychology, 6, 1490. https://doi.org/10.3389/fpsyg.2015.01490

Ogihara, Y., \& Kusumi, T. (2020). The developmental trajectory of self-esteem across the life span in Japan: Age differences in scores on the Rosenberg self-esteem scale from adolescence to old age. Frontiers in Public Health, 8, 132. https://doi.org/ $10.3389 /$ fpubh.2020.00132

Open Science Collaboration. (2012). An open, large-scale, collaborative effort to estimate the reproducibility of psychological science. Perspectives on Psychological Science, 7, 657-660. https://doi.org/10.1177/1745691612462588

Open Science Collaboration. (2015). Estimating the reproducibility of psychological science. Science, 349. https://doi. org/10.1126/science.aac4716

Park, Y., Kim, T. S., \& Park, S. W. (2016). Change in goal orientation of Korean high school athletes: A cross-temporal metaanalysis, 1999-2014. Personality and Individual Differences, 94, 342-347. https://doi.org/10.1016/j.paid.2016.02.003

Talhelm, T. (2020). Emerging evidence of cultural differences linked to rice versus wheat agriculture. Current Opinion in Psychology, 32, 81-88. https://doi.org/10.1016/j.copsyc.2019.06.031

Taras, V., Steel, P., \& Kirkman, B. L. (2012). Improving national cultural indices using a longitudinal meta-analysis of Hofstede's dimensions. Journal of World Business, 47, 329-341. https://doi.org/10.1016/j.jwb.2011.05.001

Twenge, J. M., Abebe, E. M., \& Campbell, W. K. (2010). Fitting in or standing out: Trends in American parents' choices for children's names, 1880-2007. Social Psychological and Personality Science, 1, 19-25. https://doi.org/10.1177/ 1948550609349515

Twenge, J. M., Dawson, L., \& Campbell, W. K. (2016). Still standing out: Children's names in the United States during the Great Recession and correlations with economic indicators. Journal of Applied Social Psychology, 46, 663-670. https:// doi.org/10.1111/jasp.12409

Varnum, M. E., \& Kitayama, S. (2011). What's in a name? Popular names are less common on frontiers. Psychological Science, 22, 176-183. https://doi.org/10.1177/0956797610395396

Yuki, M., \& Schug, J. (2020). Psychological consequences of relational mobility. Current Opinion in Psychology, 32, 129-132. https://doi.org/10.1016/j.copsyc.2019.07.029

Cite this article: Ogihara Y (2022). Common names decreased in Japan: Further evidence of an increase in individualism. Experimental Results, 3, e5, 1-11. https://doi.org/10.1017/exp.2021.27 


\title{
Peer Reviews
}

\author{
Reviewing editor: Prof. April Dye \\ Carson-Newman University, Psychology, 1646 Russell Ave, Jefferson Cty, Tennessee, United States, 37760
}

This article has been accepted because it is deemed to be scientifically sound, has the correct controls, has appropriate methodology and is statistically valid, and has been sent for additional statistical evaluation and met required revisions.

doi:10.1017/exp.2021.27.pr1

\section{Review 1: Common names decreased in Japan: Further evidence of an increase in individualism}

Reviewer: Dr. Hiroshi Yokomichi MD, PhD, MPH, DPH, FRSM

University of Yamanashi, Department of Health Sciences, 1110 Shimokato, Chuo City, Yamanashi, Japan, 4093898

Date of review: 28 July 2021

(C) The Author(s), 2021. Published by Cambridge University Press. This is an Open Access article, distributed under the terms of the Creative Commons Attribution licence (http://creativecommons.org/licenses/by/4.0), which permits unrestricted re-use, distribution and reproduction, provided the original article is properly cited.

Conflict of interest statement. None.

Comments to the Author: Doctor Ogihara Y wrote a manuscript about trend of frequency of common names of Japanese people, in relation to individualism. I would like to provide comments to improve the manuscript.

[Major]

1. Figures 1 and 2: Are the coefficients statistically significantly negative? In other words, are the declining trends statistically significant?

2. Methods: I wonder if the researcher disclose how he determined common names. Could it be described briefly?

3. Providing common names of both sexes would assist readers' understanding.

4. Could the researcher show diversity index to explain that diversity of name has been increased.

5. Discussion could contain more context for publication. Could the researcher compare the results from those of the other study, please?

6. Discussion: Apart from the present results, why the researcher consider that Japanese people have become more individual? Could he provide another evidence for the consideration, please?

7. Why have Japanese people become individual? Is it external pressure, declining economy, collapse of the family system, natural course of development of the nation?

This study may reflect real Japanese appearance. However, I hit upon many questions in reading this manuscript. I believe that answering to my question would widen range of readers. 


\section{Score Card}

Presentation

3.2

Is the article written in clear and proper English? (30\%)

Is the data presented in the most useful manner? (40\%) 2/5

Does the paper cite relevant and related articles appropriately? (30\%) 4/5

Context

4.0

Does the title suitably represent the article? (25\%)

Does the abstract correctly embody the content of the article? (25\%) 4/5

$\begin{array}{ll}\text { Does the introduction give appropriate context? }(25 \%) & 3 / 5\end{array}$

Is the objective of the experiment clearly defined? (25\%) 4/5

Analysis

2.2

Does the discussion adequately interpret the results presented? (40\%)

Is the conclusion consistent with the results and discussion? (40\%)

Are the limitations of the experiment as well as the contributions of the

experiment clearly outlined? (20\%) 


\section{Review 2: Common names decreased in Japan: Further evidence of an increase in individualism}

Reviewer: Mr. Amrit Jha MA (iD)

Lalit Narayan Mithila University, Psychology, C.M. College, Post Graduate Department of Psychology, Darbhanga, Bihar, India, 846004

Date of review: 23 August 2021

(C) The Author(s), 2021. Published by Cambridge University Press. This is an Open Access article, distributed under the terms of the Creative Commons Attribution licence (http://creativecommons.org/licenses/by/4.0), which permits unrestricted re-use, distribution and reproduction, provided the original article is properly cited.

Conflict of interest statement. Reviewer declares none.

Comments to the Author: The idea of the manuscript seems quite exciting at the time when the western influence on the eastern part of the world is hugely observed. There is no denying that with the passage of the time, the Asiatic cultures has imported more from the Western counterpart than the exports. In this continuum, the present article rightly explores one of the rising individual trends in Japan by including a vast sample and a large time frame. However, the author need to address the following concerns:

1. The article lacks a convincing rationale. The author has cited his/her own work as the only rationale. This needs a relook by mentioning other works as well so as to posit a holistic rationale.

2. The manuscript mention no reason/suitable discussion for the findings and lacks compelling arguments for the same. The author may also mention the other cultural factors, if any, that has contributed in such naming.

3. No limitations and implications of the findings has been mentioned.

4. Under the reference section, author's own work has been cited fifteen times compared to combined twelve other references. This looks an overreach of self-citations. Author may justify or rectify it.

5. As instructed to the authors, the journal name need to be in italics in the references.

\section{Score Card}

Presentation

Is the article written in clear and proper English? (30\%)

Is the data presented in the most useful manner? (40\%)

Does the paper cite relevant and related articles appropriately? (30\%)

\section{Context}

Does the title suitably represent the article? (25\%)

Does the abstract correctly embody the content of the article? (25\%)

Does the introduction give appropriate context? (25\%)

Is the objective of the experiment clearly defined? (25\%) 
Analysis

2.6

Does the discussion adequately interpret the results presented? (40\%)

Is the conclusion consistent with the results and discussion? (40\%)

Are the limitations of the experiment as well as the contributions of the experiment clearly outlined? (20\%) 